\title{
MARCADORES CONVERSACIONAIS DE MODALIDADE DEÔNTICA E VOLITIVA: UMA PROPOSTA DE CLASSIFICAÇÃO COM BASE NA TIPOLOGIA DAS MODALIDADES DE HENGEVELD
}

André Silva Oliveira ${ }^{1}$

RESUMO: Este trabalho se propõe a descrever e analisar a existência de marcadores conversacionais de modalidade volitiva a partir do que é proposto, tradicionalmente, acerca dos marcadores conversacionais de modalidade deôntica. Nesse sentido, buscou-se fundamentação teórica necessária na tipologia das modalidades proposta por Hengeveld (2004). Para isso, recorreu-se às entrevistas concedidas pelo Papa Francisco nas Conferencias de Prensa realizadas em suas viagens apostólicas. Após a leitura das entrevistas que compuseram o corpus e com base nos tipos de marcadores conversacionais de modalidade deôntica encontrados, definiu-se que os marcadores conversacionais de modalidade volitiva se referem aos afetos, desejos, vontades e intenções do falante frente ao que lhe é proposto na interação discursiva; enquanto os de modalidade deôntica refletem as obrigações, permissões e proibições inerentes ao falante ou aos eventos descritos no momento de fala.

PALAVRAS-CHAVE: Marcadores Conversacionais. Modalidade Deôntica. Modalidade Volitiva.

\section{INTRODUÇÃO}

$\mathrm{Na}$ literatura linguística, os marcadores conversacionais de modalidade deôntica são ditos como aqueles que refletem as atitudes do falante no que diz respeito à expressão de seus desejos, vontades, afetos e obrigações em relação ao que lhe é proposto na interação discursiva. Nesse sentido, este trabalho propõe-se a descrever e analisar a existência de marcadores conversacionais de modalidade volitiva com base no que é proposto, tradicionalmente, sobre os marcadores conversacionais de modalidade deôntica, considerando, para isso, a tipologia das modalidades de Hengeveld (2004).

De acordo com o Hengeveld (2004), a categoria modalidade pode ser delimitada com base em dois parâmetros principais: (i) o domínio semântico, que se refere ao tipo de avaliação que se faz do enunciado modalizado, em que a categoria modalidade se subdivide em epistêmica, evidencial, deôntica, volitiva e facultativa; e (ii) a orientação modal, que é relativa à perspectiva que se faz do enunciado modalizado, podendo estar orientada para o Participante, o Evento e a Proposição. Desse modo, a partir dos traços semânticos propostos, procura-se caracterizar os marcadores conversacionais de modalidade deôntica e, assim, propor os marcadores conversacionais de modalidade volitiva.

Para isso, preferiu-se por todas as Conferencias de Prensa realizadas pelo Papa Francisco em espanhol, conferências estas realizadas entre os anos de 2014 e 2019, estando disponibilizadas na página oficial do Papa Francisco no site do Vaticano. A escolha dessas conferências se deu em razão de se acreditar que o Santo Padre, ao responder às perguntas feitas pelos

1 Instituição: Universidade Federal do Ceará, Orcid: https://orcid.org/0000-0003-3448-0658, E-mail: andrethtzn@gmail.com 
jornalistas, na maioria, representantes de jornais e empresas de comunicação, poderia tanto fazer uso de marcadores conversacionais que expressassem suas atitudes no que diz respeito às suas obrigações, ao que é permitido ou proibido de realizar quanto manifestar seus afetos, desejos, vontades e intenções frente ao que lhe é proposto durante a interação comunicativa.

Partindo do pressuposto de redefinir os marcadores conversacionais de modalidade deôntica, far-se-á, na primeira seção, uma abordagem acerca dos marcadores conversacionais deônticos na seara linguística. Na sequência, discorrer-se-á sobre a tipologia das modalidades de Hengeveld (2004) e, com base nela, uma proposta de classificação entre marcadores conversacionais deônticos e volitivos. Posteriormente, abordar-se-á acerca da metodologia empregada nesta pesquisa, dissertando acerca do corpus que compõe o universo da pesquisa e a apreciação das categorias de análise. Em seguida, apresentar-se-á, de forma qualitativa, os resultados encontrados, discutindo-os à luz dos pressupostos de Hengeveld (2004). Feito isso, passar-se-á às conclusões com base na seção referente aos resultados e discussões.

\section{MARCADORES CONVERSACIONAIS DE MODALIDADE DEÔNTICA}

$\mathrm{Na}$ seara linguística, os marcadores conversacionais são entendidos, conforme Zorraquino e Portolés (1999), como estruturadores de informação, agindo, portanto, como conectores e reguladores daquilo que é veiculado pelos participantes do discurso (falante e ouvinte). Além disso, podem atuar também, segundo os autores, como operadores de argumentação e, obviamente, como marcadores discursivos. Em outras palavras, os autores defendem que os marcadores conversacionais se constituem como unidades invariáveis que não exercem algum tipo de função sintática na oração, sendo, dessa forma, elementos marginais, restringindo-se apenas à função de guiar as inferências realizadas na comunicação. Nesse sentido, os autores delimitam os marcadores conversacionais em quatro tipos: enfocadores de alteridade, metadiscursivos conversacionais, modalidade epistêmica e modalidade deôntica. Por ser de interesse desta pesquisa apenas os marcadores conversacionais de modalidade deôntica, deter-se-á somente neles.

Nas palavras de Zorraquino e Portolés (1999), a função dos marcadores conversacionais de modalidade deôntica é a de manifestar as atitudes do falante com relação à expressão da vontade, do afetivo, em que ele aceita e admite (de maneira consciente ou não) aquilo que se interpõe no fragmento do discurso ao qual remete. Em consonância com os autores, Abarca Cea (2012) especifica que os marcadores conversacionais de modalidade deôntica ou de aceitação refletem as atitudes do falante perante a sua expressão de vontade ou de afetividade, sendo, por meio deles, que se conhece se o falante admite ou não o que se infere do discurso. Conforme Saíz e Pasamar (2012), os marcadores conversacionais de modalidade deôntica, além de incluir os valores que refletem às atitudes volitivas e afetivas ao discurso precedente, podem também ser empregados para demonstrar atitudes de aproximação com o ouvinte.

Nas palavras de Folkesson (2014), os principais marcadores conversacionais de modalidade deôntica em língua espanhola são: bueno, bien, vale e de acuerdo; haja vista que, no encadeamento discursivo, eles são relativos à manifestação de conceitos que tem relação com a vontade do sujeito, indicando, dessa forma, se o falante aceita ou rechaça a informação proposta, um oferecimento, uma súplica, um pedido etc. Conforme Mendonza (2014), os marcadores conversacionais de modalidade deôntica indicam as atitudes volitivas do falante em 
relação aos demais participantes do discurso, podendo ser empregados, além dos marcadores bueno, bien, vale e de acuerdo, alguns advérbios terminados em -mente, como definitivamente; o que pode ser averiguado nos exemplos: (1) Es decir, de captar ciertos beneficios materiales, ¿no? Bueno, mejor educación, en fin; (2) De acuerdo. Y ahora hay un fenómeno que se verifica, por ejemplo, en Bolivia en líneas generales; (3) E: No es esa generación. ¿No es esa tendencia algo dañina para las regiones? I: Definitivamente; e (4) Y bien que podría ser éste, un ejemplo que esperemos que tenga buen resultado (MENDONZA, 2014, p. 156-167). ${ }^{2}$

De acordo com Valencia (2015), alguns marcadores conversacionais de modalidade deôntica podem ser empregados para demonstrar ratificação, autocorreção ou antecipação de um enunciado, entre eles, tem-se: bueno, claro e por supuesto; como nos exemplos: (5) La gente es muy acogedora y muy simpática, sí. Bueno, a veces que están un poco antipáticos, pero, en general, la gente es acogedora; (6) Hacíamos fiestas temáticas, a veces nos disfrazábamos, a veces, este ... hacíamos una fiesta hawaiana, a veces ... claro, la poca gente que tenía el dinero dentro del grupo; e (7) El secreto no es si tienes más dinero o tienes menos dinero, si tienes claro que... que... por supuesto que el dinero ayuda en muchas cosas (VALENCIA, 2015, p. 106). ${ }^{3}$

Conforme Álvarez-Ejzenberg (2015), os marcadores de modalidade deôntica podem também indicar fragmentos do discurso que implicam em uma proposta ou uma avaliação que, por sua vez, assinalam se o falante aceita ou não aquilo que se infere a partir do enunciado ao qual esses marcadores deônticos remetem. Para esses casos, a autora infere que o marcador dale é o mais empregado, como nos exemplos: (8) PEPE: ¡Vamos, Beto!, me vas a decir que nunca fuiste capaz de fajar a tu mujer. ¿Ni siquiera un bifecito? Chiquitito así. (Pone la mano.). BETO: Bueno, sí, un día le pegué un bifecito, dale (ÁLVAREZ-EJZENBERG, 2015, p. 60). ${ }^{4}$

León-Castro (2019) afirma que os marcadores conversacionais de modalidade deôntica podem ser empregados como marcadores de alteridade, especificamente em casos nos quais o falante deseja ser mais assertivo em relação ao que ele aceita ou recusa, tendo em vista o que lhe é proposto pelo ouvinte, como nos exemplos: (9) O plastas, voz que también los define muy bien: "Pepe es un tío plasta". Bueno, pues ahora tenemos ya suelto, en todo lo suyo, al pesado de Semana Santa, como más tarde habremos de tener al de Feria (LEÓN-CASTRO, 2019, p. 48). ${ }^{5}$

Por fim, Oliveira (2019) especifica que os marcadores de modalidade deôntica podem expressar obrigações que são inerentes ao falante e que são admitidas por ele com base no discurso remetente, podendo ser empregados os seguintes marcadores: sí, claro, de acuerdo, por

2 Tradução livre: (1) Ou seja, para capturar certos benefícios materiais, certo? Bom, melhor educação, pelo menos; (2) Concordo. E agora há um fenômeno verificado, por exemplo, na Bolívia em geral; (3) E: Não é essa geração ... Essa tendência não é algo prejudicial para as regiões? I: Definitivamente; e (4) E bem que este poderia ser um exemplo que esperamos que tenha um bom resultado (MENDONZA, 2014, p. 156-167).

3 Tradução livre: (5) As pessoas são muito acolhedoras e muito agradáveis, sim. Bem, às vezes eles são um pouco hostis, mas, em geral, as pessoas são acolhedoras; (6) Tivemos festas temáticas, às vezes nos vestimos, às vezes, isso ... tivemos uma festa havaiana, às vezes ... é claro, as poucas pessoas que tinham dinheiro no grupo; e (7) O segredo não é se você tem mais dinheiro ou tem menos dinheiro, se você está claro que ... isso ... é claro que o dinheiro ajuda em muitas coisas (VALENCIA, 2015, p. 106).

4 Tradução livre: (8) PEPE: Vamos lá, Beto! Você me dirá que nunca foi capaz de bater na sua esposa. Nem um tapinha? Pouquinho assim. (Ele coloca a mão.) BETO: Bem, sim, um dia eu bati nela, Pois é (ÁLVAREZ-EJZENBERG, 2015, p. 60). 5 Tradução livre: (9) Ou chata, uma palavra que também define muito bem: "Pepe é um cara chato". Bom, agora já lançamos, por si só, a Páscoa chata, como teremos mais tarde na Feira (LEÓN-CASTRO, 2019, p. 48). 
supuesto, definitivamente, etc.; como no exemplo: (10) Papa Francisco: [...] Yo siento que existe el agotamiento, pero no le tengo miedo. Debo continuar hablando de la verdad y de cómo son las cosas. Entrevistador: ¿Es su deber? Papa Francisco: Sí, es mi deber. Lo siento dentro de mí. No es un mandamiento, pero como personas todos tenemos que hacerlo (OLIVEIRA, 2019 , p. 20). ${ }^{6}$

Dessa forma, averígua-se que os marcadores conversacionais de modalidade deôntica são aqueles que refletem as atitudes do falante no que diz respeito à expressão de suas vontades, seus desejos, seus afetos e suas obrigações em relação ao que lhe é proposto. No entanto, acredita-se que seja possível uma redefinição no que tangem aos marcadores conversacionais deônticos, tendo em vista a tipologia das modalidades de Hengeveld (2004), que será discutida na próxima seção.

\section{READEQUAÇÃO DOS MARCADORES CONVERSACIONAIS DE MODALIDADE DEÔNTICA COM BASE NA TIPOLOGIA DAS MODALIDADES DE HENGEVELD}

Na tipologia das modalidades de Hengeveld (2004), a categoria modalidade é descrita e analisada com base em dois parâmetros: (i) o domínio semântico, que diz respeito à perspectiva a partir da qual a avaliação do enunciado modalizado é feita; e (ii) a orientação modal, que se refere à parte do enunciado que é modalizada.

Em relação ao primeiro parâmetro, Hengeveld (2004) estabelece que a categoria modalidade pode ser dividida em cinco tipos: (i) facultativa, que se refere às capacidades intrínsecas ou adquiridas do participante expresso pelo predicado ou de algum evento em termos das circunstâncias de concretização deste evento no mundo; (ii) epistêmica, que é relativa aos conhecimentos e crenças do falante acerca do mundo real, sendo por ele avaliado em termos de verdade ou falsidade; (iii) evidencial, que diz respeito à fonte da informação que é reportada pelo falante ou cujo material cognitivo a ele pertence; (iv) deôntica, que é referente às regras e normas de conduta que são socialmente, legalmente e moralmente aceitas, podendo ser prescritas ou avaliadas pelo falante ou por uma fonte modal que lhe é externa; e (iv) volitiva, que está relacionada ao que é desejável ou indesejável da parte do falante ou do participante designado pelo predicado, podendo ser um desejo relativo ao mundo real ou a um mundo imaginário/fictício.

No tocante ao segundo parâmetro, Hengeveld (2004) especifica que a categoria modalidade pode apresentar três tipos de orientação: (i) orientada para o Participante, que afeta a parte relacional do enunciado, em que há uma relação intrínseca entre (as propriedades de) um dado participante e um evento, e a potencialização desse evento por parte deste participante; (ii) orientada para o Evento, que afeta a descrição de um evento contido no enunciado modalizado, referindo-se, portanto, à parte descritiva e objetiva deste, sem que haja uma apreciação desse evento por parte do falante; e (iii) orientada para a Proposição, que afeta o conteúdo proposicional do enunciado modalizado, isto é, refere-se à parte do discurso que representa o ponto de vista, as crenças, os desejos e as convicções do falante, relacionando-se, dessa forma, com o grau de comprometimento dele em relação à proposição contida no enunciado modalizado.

6 Tradução livre: (10) Papa Francisco: [...] sinto que há exaustão, mas não tenho medo disso. Devo continuar falando sobre a verdade e como estão as coisas. Entrevistador: É seu dever? Papa Francisco: Sim, é meu dever. Eu sinto isso dentro de mim. Não é um mandamento, mas como pessoas, todos temos que fazer isso (OLIVEIRA, 2019, p. 20). 
Por ser do interesse desta pesquisa apenas as modalidades deôntica e volitiva, deter-se-á nesses dois tipos modais, especificando-os, primeiramente, em relação à orientação modal e, posteriormente, no que diz respeito ao domínio semântico.

Em relação à orientação modal, a modalidade deôntica pode estar orientada para: (i) o Participante, quando recai sobre o participante expresso no predicado a obrigação ou a permissão de realizar o evento, ou a proibição de não o realizar, como no exemplo: Cada día, sin ahorrar tiempo, debemos estar frente a Jesús, llevarle las personas, las situaciones, como canales siempre abiertos entre él y nuestro pueblo. A través de la oración le damos al Señor la ciudadanía dondequiera que vivamos; ${ }^{7}$ e (ii) o Evento, quando o falante reporta a obrigatoriedade de um evento, mas sem que ele faça uma apreciação de cunho pessoal, apenas manifestando o estatuto objetivo deste evento, como no exemplo: En la Iglesia Católica de rito latino, el celibato eclesiástico, es decir, la renuncia al matrimonio y la promesa de castidad, es obligatorio para los sacerdotes desde el II Concilio de Letrán, en 1139. ${ }^{8}$

Por sua vez, a modalidade volitiva pode estar orientada para: (i) o Participante, quando o participante expresso no enunciado modalizado manifesta o desejo de realizar o evento descrito pelo predicado, como no exemplo: Por eso, queridos hermanos y hermanas, deseo rezar con vosotros a Cristo en esta Cuaresma ${ }^{9}$ (ii) o Evento, quando o falante reporta a desejabilidade de um dado evento, mas sem que ele faça uma apreciação de cunho pessoal deste evento, como no exemplo: Es deseable que la vida consagrada se muestre cada vez más llena de alegría y de Espíritu Santo, se lance con brío por los caminos de la misión, se acredite por la fuerza del testimonio vivido; ${ }^{10} \mathrm{e}$ (iii) a Proposição, quando o falante faz uma apreciação acerca de um evento desejável, localizado apenas em sua mente e irrealizável do ponto de vista factual, como no exemplo: Gracias. Gracias por este hermoso encuentro y pensando en el papa Juan, quisiera que la bendición que les doy ahora sea una caricia del Señor para cada uno de ustedes. ${ }^{11}$

Tomando por base o domínio semântico, constata-se que a modalidade deôntica é relativa às regras e normas de conduta impostas socialmente, legalmente e moralmente, sendo a ela atribuídos valores como obrigação, permissão e proibição, por isso, atua no eixo da conduta (dever-fazer/não-dever-fazer); enquanto a modalidade volitiva se refere ao que é (in)desejável, sendo a ela atribuídos valores como desejo, vontade e intenção, atuando, dessa forma, no eixo da volição (querer-desejar/querer-fazer).

Partindo dessa definição, pode-se redefinir o que já é proposto, na tradição linguística, acerca dos marcadores conversacionais de modalidade deôntica, classificando-os, desse modo, em dois tipos distintos: (i) os marcadores conversacionais de modalidade deôntica, que refletem as atitudes do falante no que diz respeito às suas obrigações, ao que é permitido ou

\footnotetext{
7 Tradução livre: Todos os dias, sem economizar tempo, devemos colocar-nos diante de Jesus, trazer pessoas, situações, como canais sempre abertos entre ele e nosso povo. Pela oração, damos ao Senhor cidadania onde quer que vivamos (Papa Francisco). Disponível em: <https://bit.ly/2F3nob0>. Acesso em: 28 mar. 2020.

8 Tradução livre: Na Igreja Católica do Rito Latino, o celibato eclesiástico, isto é, a renúncia ao casamento e a promessa de castidade, é obrigatório para os padres desde o Segundo Concílio Lateranense, em 1139 (Papa Francisco). Disponível em: $<$ https://bit.ly/2QpxNms>. Acesso em: 28 mar. 2020.

9 Tradução livre: Portanto, queridos irmãos e irmãs, desejo rezar convosco a Cristo nesta Quaresma (Papa Francisco). Disponível em: <https://bit.ly/2u27L1j>. Acesso em: 28 mar. 2020.

10 Tradução livre: É desejável que a vida consagrada seja mostrada cada vez mais cheia de alegria e que o Espírito Santo seja lançado rapidamente pelos caminhos da missão, credenciados pela força do testemunho vivido (Papa Francisco). Disponível em: <https://bit.ly/2VfO41i>. Acesso em: 28 mar. 2020.

11 Tradução livre: Obrigado. Obrigado por esta bela reunião e pensamento do papa João. Quisera que a bênção que lhe dou agora seja uma carícia do Senhor para cada um de vocês (Papa Francisco). Disponível em: <https://bit.ly/2ZwlxVr>. Acesso em: 28 mar. 2020.
} 
proibido de realizar frente ao que lhe é proposto no discurso; e (ii) os marcadores conversacionais de modalidade volitiva, que refletem as atitudes do falante no que diz respeito aos seus afetos, desejos, vontades e intenções perante o que lhe é proposto no discurso.

Considerando a redefinição dos marcadores conversacionais de modalidade deôntica e a proposta de marcadores conversacionais de modalidade volitiva com base em Hengeveld (2004), passar-se-á, na seção seguinte, à metodologia que será empregada nesta pesquisa, a delimitação do corpus e a apreciação das categorias de análise.

\section{METODOLOGIA}

Esta pesquisa propõe-se a descrever e analisar a existência de marcadores conversacionais de modalidade volitiva com base no que é proposto, tradicionalmente, sobre os marcadores conversacionais de modalidade deôntica. Para isso, optou-se pelas Conferencias de Prensa realizadas pelo Papa Francisco, que se referem a entrevistas concedidas pelo Santo Padre aos jornalistas por meio de uma coletiva de imprensa e que são realizadas ao término das suas viagens apostólicas. Sendo assim, foram selecionadas todas as conferências concedidas pelo Sumo Pontífice até o presente momento, isto é, as que foram realizadas entre os anos de 2014 e 2019. ${ }^{12}$

Na sequência, o Quadro 01 traz o detalhamento das Conferencias de Prensa que fizeram parte do universo desta pesquisa:

Quadro 01: As Conferencias de Prensa do Papa Francisco entre os anos de 2014 e 2019

\begin{tabular}{|c|c|c|}
\hline Sigla & Conferencia de Prensa & Link de acesso \\
\hline $\mathrm{CP} 1$ & $\begin{array}{l}\text { RUEDA DE PRENSA DEL SANTO PADRE FRANCISCO EN } \\
\text { EL VUELO DE REGRESO DE TIERRA SANTA ( } 26 \text { de mayo } \\
\text { de 2014) }\end{array}$ & Disponível em: https://bit.ly/34YT5fU \\
\hline $\mathrm{CP} 2$ & $\begin{array}{l}\text { RUEDA DE PRENSA DEL SANTO PADRE FRANCISCO EN } \\
\text { EL VUELO DE COREA A ROMA (18 de agosto de } 2014)\end{array}$ & Disponível em: https://bit.ly/2ERif5B \\
\hline $\mathrm{CP} 3$ & $\begin{array}{l}\text { RUEDA DE PRENSA DEL SANTO PADRE FRANCISCO DU- } \\
\text { RANTE EL VUELO DE REGRESO A ROMA ( } 21 \text { de septiembre } \\
\text { de 2014) }\end{array}$ & $\begin{array}{l}\text { Disponível em: https://bit.ly/2ETu- } \\
\text { q1K }\end{array}$ \\
\hline $\mathrm{CP} 4$ & $\begin{array}{l}\text { CONFERENCIA DE PRENSA DEL SANTO PADRE DURAN- } \\
\text { TE EL VUELO DE MANILA A ROMA (19 de enero de 2015) }\end{array}$ & Disponível em: https://bit.ly/2saYByY \\
\hline CP5 & $\begin{array}{l}\text { CONFERENCIA DE PRENSA DEL SANTO PADRE DURAN- } \\
\text { TE EL VUELO DE REGRESO DE SARAJEVO (6 de junio de } \\
\text { 2015) }\end{array}$ & $\begin{array}{l}\text { Disponível em: https://bit.ly/35Ww- } \\
\text { Jx9 }\end{array}$ \\
\hline CP6 & $\begin{array}{l}\text { COLOQUIO DEL SANTO PADRE CON LOS PERIODISTAS } \\
\text { DURANTE EL VUELO DE REGRESO DE ASUNCIÓN A } \\
\text { ROMA ( } 13 \text { de julio de } 2015)\end{array}$ & Disponível em: https://bit.ly/2ERgEgj \\
\hline $\mathrm{CP} 7$ & $\begin{array}{l}\text { CONFERENCIA DE PRENSA DEL SANTO PADRE DURAN- } \\
\text { TE EL VUELO DE REGRESO A ROMA ( } 27 \text { de septiembre de } \\
\text { 2015) }\end{array}$ & Disponível em: https://bit.ly/2tJbccP \\
\hline CP8 & $\begin{array}{l}\text { CONFERENCIA DE PRENSA DEL SANTO PADRE DURAN- } \\
\text { TE EL VUELO DE REGRESO A ROMA ( } 30 \text { de noviembre de } \\
\text { 2015) }\end{array}$ & $\begin{array}{l}\text { Disponível em: https://bit.ly/35WZ- } \\
\text { qtL }\end{array}$ \\
\hline $\mathrm{CP9}$ & $\begin{array}{l}\text { CONFERENCIA DE PRENSA DEL SANTO PADRE DURAN- } \\
\text { TE EL VUELO DE REGRESO A ROMA (17 de febrero de 2016) }\end{array}$ & $\begin{array}{l}\text { Disponível em: https://bit.ly/2E- } \\
\text { PLwO4 }\end{array}$ \\
\hline CP10 & $\begin{array}{l}\text { CONFERENCIA DE PRENSA DEL SANTO PADRE DURAN- } \\
\text { TE EL VUELO DE REGRESO A ROMA (16 de abril de 2016) }\end{array}$ & Disponível em: https://bit.ly/37csQo2 \\
\hline CP11 & $\begin{array}{l}\text { CONFERENCIA DE PRENSA DEL SANTO PADRE DURAN- } \\
\text { TE EL VUELO DE REGRESO A ROMA ( } 26 \text { de junio de } 2016)\end{array}$ & $\begin{array}{l}\text { Disponível em: https://bit.ly/2SsvM- } \\
\text { bM }\end{array}$ \\
\hline
\end{tabular}

12 As Conferencias de Prensa do Papa Francisco podem ser acessadas na página oficial do Vaticano. Disponível em: <http:// w2.vatican.va/content/vatican/es.html>. Acesso em: 25 dez. 2019. 


\begin{tabular}{|c|c|c|}
\hline $\mathrm{CP} 12$ & $\begin{array}{l}\text { CONFERENCIA DE PRENSA DEL SANTO PADRE DURAN- } \\
\text { TE EL VUELO DE REGRESO A ROMA (31 de julio de 2016) }\end{array}$ & https://bit.ly/ \\
\hline $\mathrm{CP}$ & & Disponível em: https://bit.ly/2SmqoHj \\
\hline $\mathrm{CP} 1$ & $\begin{array}{l}\text { CONFERENCIA DE PRENSA DEL SANTO PADRE DURAN- } \\
\text { TE EL VUELO DE REGRESO A ROMA (1 de noviembre de } \\
\text { 2016) }\end{array}$ & Disponível em: https://bit.ly/2PTCiXn \\
\hline $\mathrm{CP} 15$ & $\begin{array}{l}\text { ENTREVISTA DEL SANTO PADRE CON LOS PERIODISTAS } \\
\text { DURANTE EL VUELO DE REGRESO A ROMA ( } 29 \text { de abril } \\
\text { de 2017) }\end{array}$ & $\begin{array}{l}\text { Disponível em: } \\
\text { ly/37880WD }\end{array}$ \\
\hline CP16 & $\begin{array}{l}\text { ENCIA DE PRENSA DEL SANTO PADRE DURAN- } \\
\text { JELO DE REGRESO A ROMA (13 de mayo de 2017) }\end{array}$ & 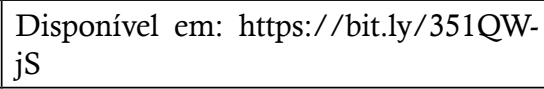 \\
\hline $\mathrm{CP} 1$ & $\begin{array}{l}\text { CONFERENCIA DE PRENSA DEL SANTO PADRE DURAN- } \\
\text { TE EL VUELO DE REGRESO A ROMA (10 de septiembre de } \\
\text { 2017) }\end{array}$ & $\begin{array}{l}\text { Disponível em: https://bit.ly/2ZnN- } \\
\text { lLD }\end{array}$ \\
\hline CP18 & DU- & Disponível em: https://bit.ly/2Sq0e6p \\
\hline CP19 & $\begin{array}{l}\text { CONI } \\
\text { TE EI }\end{array}$ & Disponível em: https://bit.ly/2StOpvZ \\
\hline СР20 & $\begin{array}{l}\text { CONFE } \\
\text { TE EL }\end{array}$ & Disponível em: https://bit.ly/2PVjNSh \\
\hline CP21 & $\begin{array}{l}\text { CONF } \\
\text { TE EL }\end{array}$ & Disponível em: https://bit.ly/2t5N16I \\
\hline $\mathrm{CP} 22$ & $\begin{array}{l}\text { CONFERENCIA D } \\
\text { TE EL VUELO DE } \\
\text { 2018) }\end{array}$ & Disponível em: https://bit.ly/35XrPjk \\
\hline $\mathrm{CP} 23$ & 9) & Disponível em: https://bit.ly/378Cnfx \\
\hline СР24 & $\begin{array}{l}\text { CONF } \\
\text { TE EL }\end{array}$ & Disponível em: https://bit. \\
\hline $\mathrm{CP} 25$ & $\begin{array}{l}\text { CONFERENCIA DE PRENSA DEL SANTO PADRE DURAN- } \\
\text { TE EL VUELO DE REGRESO A ROMA (31 de marzo de 2019) }\end{array}$ & $\begin{array}{l}\text { Disponível em: } \mathrm{h} \\
\text { GF }\end{array}$ \\
\hline $\mathrm{CP} 2$ & $\begin{array}{l}\text { CONFERENCIA DE PRENSA DEL SANTO PADRE DURAN- } \\
\text { TE EL VUELO DE REGRESO A ROMA ( } 7 \text { de mayo de 2019) }\end{array}$ & $\begin{array}{l}\text { Disponível em: https://bit.ly/2Q- } \\
\text { gYhXn }\end{array}$ \\
\hline $\mathrm{CP} 2$ & $\begin{array}{l}\text { CONFERENCIA DE PRENSA DEL SANTO PADRE DURAN- } \\
\text { TE EL VUELO DE VUELTA ( } 10 \text { de septiembre de 2019) }\end{array}$ & $\begin{array}{l}\text { Disponível em: https://bit.ly/34XXl- } \\
\text { ME }\end{array}$ \\
\hline $\mathrm{CP} 2$ & $\begin{array}{l}\text { RUEDA DE PRENSA DEL SANTO PADRE DURANTE EL } \\
\text { VUELO DE REGRESO ( } 26 \text { de noviembre de 2019) }\end{array}$ & Disponível em: https://bit. \\
\hline
\end{tabular}
Fonte: Elaborado pelo autor

Em relação à Conferencia de Prensa, entende-se, com base em Molero Hermosilla (2005), que ela se caracteriza como uma reunião convocada por uma fonte informativa (o Vaticano, representado pela pessoa do Papa Francisco) para dar conta de uma determinada notícia aos meios de comunicação (questionamentos relevantes e precisos acerca do que é veiculado pelo Papa Francisco por meio de seus discursos e homilias em suas viagens apostólicas). Nesse sentido, as Conferencias de Prensa facilitam o contato direto da entidade (o Vaticano) com os profissionais da informação (jornalistas, periodistas, etc.), constituindo-se, portanto, como um meio idôneo para a explicitação de conteúdos pouco esclarecidos na fala do orador (o Papa Francisco).

Desse modo, pondera-se que o Sumo Pontífice pode, em suas Conferencias de Prensa, fazer uso tanto de marcadores conversacionais de modalidade deôntica, no intuito de expressar suas atitudes no que diz respeito às suas obrigações, ao que é permitido ou proibido 
de realizar; como utilizar marcadores conversacionais de modalidade volitiva, em razão de manifestar seus afetos, desejos, vontades e intenções frente ao que lhe é proposto no discurso.

Partindo dessa possibilidade, far-se-á a descrição e análise dos marcadores conversacionais de modalidade deôntica e volitiva de maneira qualitativa, considerando, especificamente, três categorias de análise: (i) o tipo de marcador conversacional, no caso, de modalidade deôntica e de modalidade volitiva; e (ii) o tipo de modalidade que ancora o marcador conversacional deôntico ou volitivo, que pode ser epistêmica, evidencial, deôntica, volitiva e facultativa; e (iii) o tipo de orientação modal que é qualificada no encadeamento discursivo, podendo ser orientada para o Participante, o Evento e a Proposição.

Sabendo-se da caracterização do corpus e da apreciação das categorias de análise, abordar-se-á, na seção seguinte, os resultados e discussões acerca do engendramento dos marcadores conversacionais de modalidade deôntica e volitiva nas Conferencias de Prensa do Papa Francisco.

\section{RESULTADOS E DISCUSSÕES}

A partir da descrição e análise qualitativa dos dados, constatou-se, com base nos parâmetros propostos por Hengeveld (2004), que os diferentes usos dos marcadores conversacionais de modalidade deôntica e de modalidade volitiva podem ser classificados com base em funções semânticas, tais como: (i) o valor modal (desejo, vontade, intenção, obrigação, permissão e proibição) que se infere a partir do emprego do marcador conversacional no encadeamento discursivo; (ii) o tipo de modalidade (epistêmica, evidencial, deôntica, volitiva ou facultativa) que ancora o uso do marcador conversacional; e (iii) o tipo de orientação modal (Participante, Evento ou Proposição) que aporta o uso do marcador conversacional.

Em relação aos marcadores conversacionais de modalidade deôntica, foi possível averiguar que estes remetiam aos valores modais de obrigação, permissão e proibição, como se pode atestar, respectivamente, de (1) a (3).

Em (1), há um caso de marcador conversacional de modalidade deôntica com valor modal de obrigação:

(Sagrario Ruiz de Apodaca): Quisiera preguntarle también, ya que le hemos oído hablar de poner de relieve el papel de las religiosas y de las mujeres en la iglesia estadounidense: ¿Veremos algún día mujeres sacerdotes en la Iglesia católica, como piden algunos grupos de los Estados Unidos y como sucede en otras iglesias cristianas? Gracias.

(Papa Francisco): Las mujeres sacerdote: eso no está en mis manos. El Papa san Juan Pablo II, en tiempos de discusión, después de una larga reflexión, lo dijo claro, No porque las mujeres no tengan capacidad. Pero mira: en la Iglesia son más importantes las mujeres que los hombres, porque la Iglesia es mujer, "La" Iglesia, no "El" Iglesia: la Iglesia es la esposa de Cristo, y la Virgen es más importante que los papas, los obispos y los sacerdotes. Hay algo que debo reconocer: nosotros estamos con un poco de retraso en la elaboración de una teología de la mujer. Tenemos que adelantar en esa teología. Esto sí, verdaderamente. Gracias. (CP7). ${ }^{13}$

13 Tradução livre: (Sagrario Ruiz de Apodaca): Eu também gostaria de perguntar ao senhor, uma vez que ouvimos o senhor falar sobre destacar o papel das religiosas e das mulheres na igreja norte-americana: um dia veremos mulheres sacerdotes na Igreja Católica, como alguns grupos nos Estados Unidos e como isso acontece em outras igrejas cristãs? Obrigada. (Papa Francisco): Sacerdote: isso não está nas minhas mãos. O papa João Paulo II, em tempos de discussão, após uma longa reflexão, disse claramente, não porque as mulheres não têm capacidade. Mas veja: na Igreja, as mulheres são mais importantes que os homens, porque a Igreja é uma mulher, "A Igreja", não "O" Igreja: a Igreja é a esposa de Cristo, e a Virgem é mais importante que os papas, bispos e padres. Há algo que devo reconhecer: estamos um pouco atrasados no desenvolvimento de uma teologia da mulher. Temos que avançar nessa teologia. Isso sim, certamente. Obrigado. 
Em (1), observa-se que marcador conversacional Esto sí é empregado pelo Papa Francisco para expressar o que lhe parece obrigatório em termos de reconhecer que o clero católico ainda está um pouco atrasado em relação à elaboração de uma teologia sobre a mulher. Essa obrigatoriedade, por sua vez, está respaldada por duas modalizações deônticas: Hay algo que debo reconocer e Tenemos que adelantar en esa teologia. Ambas as modalizações deônticas, cuja orientação modal é para o Participante, são instauradas por meio dos verbos modais deber+infinitivo e tener+que+infinitivo, e revelam que tanto a pessoa do Santo Padre (o que é evidenciado pelo uso da primeira pessoa do singular, debo) quanto o clero católico (representado pela marca da primeira pessoa do plural, tenemos) estão sob a obrigação de realizar o que é descrito no evento expresso pelo predicado, designadamente, reconocer e adelantar, asseverando o emprego do marcador conversacional Esto sí.

Reitera-se que outros marcadores conversacionais de modalidade deôntica também poderiam ser empregados, tais como: por supuesto, evidentemente, claro, de acuerdo, etc. Parafraseando o exemplo, isso pode ser constatado: Tenemos que adelantar en esa teología. Por supuesto/ Evidentemente/Claro/De acuerdo verdaderamente. Gracias.

Na sequência, aborda-se, em (2), um caso de marcador conversacional de modalidade deôntica com valor modal de permissão:

(Paloma García Ovejero): Bien, el próximo viaje será a Albania. Quizás Irak. Después Filipinas y Sri Lanka... Pero, ¿dónde irá en 2015? Y le digo también: Usted sabe que en Ávila y en Alba de Tormes lo esperan con ilusión: ¿pueden seguir esperándolo?

(Papa Francisco) Sí, sí... La Señora Presidenta de la República de Corea me dijo en perfecto español: "La esperanza es lo último que se pierde". Así me dijo, refiriéndose a la unificación de Corea. Lo que le puedo decir es esto: se puede esperar, pero no hay nada decidido. (CP2)..$^{14}$

Em (2), observa-se que o marcador conversacional Sí é empregado pelo Papa Francisco para expressar o que é por ele avaliado como permitido em relação à espera do povo de Ávila e Alba de Tormes para a sua visita pastoral. Por seu turno, o emprego desse marcador conversacional deôntico tem seu valor de permissão ancorado por duas modalizações deônticas, cujo valor modal também é de permissão, no caso, na pergunta feita pela jornalista: ¿Pueden seguir esperándolo?; e na resposta que é dada pelo Sumo Pontífice: Lo que le puedo decir es esto: se puede esperar. Em relação à orientação modal de ambas as modalizações deônticas que foram instauradas por meio do modal poder+infinitivo, percebe-se que há uma divergência. Na modalidade deôntica contida na pergunta, a orientação modal é para o Participante, que remete ao povo das cidades de Ávila e Alba de Tormes, em que recai sobre eles a possibilidade de permissão de esperar pela visita pastoral do Santo Padre. Em contrapartida, na modalidade deôntica contida na resposta do Papa Francisco, atesta-se que a orientação modal é para o Evento, em que, pela marca de impessoalidade "se", o Sumo Pontífice reporta a permissão relativa ao evento descrito pelo predicado, ou seja, o de esperar pela sua visita pastoral.

Tal divergência pode ser um indicativo de uma possível asseveração da permissão que recai sobre o participante expresso pela modalidade deôntica com orientação para o Participante, o que poderia produzir um efeito de sentido de que essa espera tem raiz em uma neces-

14 Tradução livre: (Paloma García Ovejero): Bem, a próxima viagem será para a Albânia. Talvez Iraque. Depois, Filipinas e Sri Lanka ... Mas para onde irá em 2015? E também digo: o senhor sabe que em Ávila e Alba de Tormes eles estão ansiosos pelo senhor: eles podem ficar esperando pelo senhor? (Papa Francisco) Sim, sim ... O Presidente da República da Coréia me disse em perfeito espanhol: "A esperança é a última coisa que morre". Então ele me disse, referindo-se à unificação da Coréia. O que posso lhe dizer é o seguinte: pode-se esperar, mas não há nada decidido. 
sidade de que o Santo Padre os visite, o que pode ser evidenciado pela repetição do marcador conversacional de modalidade deôntica (Sí, sí...) na resposta do Sumo Pontífice. No entanto, o uso da modalidade deôntica com orientação para o Evento poderia mitigar essa permissão, haja vista que não há um comprometimento do Papa Francisco em relação ao estatuto de realidade desse evento (pero no hay nada decidido), haja vista que a orientação modal para o Evento remete apenas à permissão de concretização de um evento (o que pode ser evidenciado pelo uso da modalidade epistêmica que ancora a modalidade deôntica da resposta: Lo que puedo decir es esto), sem que isso acarrete em um maior comprometimento do Santo Padre quanto à certeza da sua visita, em razão de outros compromissos vindouros.

Acredita-se que outros marcadores conversacionais de modalidade deôntica também poderiam ser empregados, tais como: por supuesto, evidentemente, claro, de acuerdo, certamente, etc. Parafraseando o exemplo, isso pode ser averiguado: Por supuesto/Evidentemente/Claro/ De acuerdo/Certamente... La Señora Presidenta de la República de Corea me dijo en perfecto español.

Em (3), discorre-se acerca de um caso de marcador conversacional de modalidade deôntica com valor de proibição:

\begin{abstract}
(Philippine De Saint-Pierre): Santo Padre, buenas tardes. Usted ha rendido homenaje a la plataforma creada por el Arzobispo, el Imán y el Pastor de Bangui, y hoy más que nunca sabemos que el fundamentalismo religioso amenaza a todo el planeta: lo hemos visto también en París. Ante este peligro, ¿cree usted que los líderes religiosos deben intervenir más en el campo politico? (Papa Francisco): Si intervenir en el campo politico significa "hacer politica», no. Que haga de sacerdote, pastor, imán, rabino: esta es su vocación. Pero se hace politica indirectamente predicando los valores, los valores verdaderos, y uno de los mayores valores es la hermandad entre nosotros. Todos somos hijos de Dios, tenemos el mismo Padre. En ese sentido, hay que hacer una politica de unidad, de reconciliación y -es una palabra que no me gusta, pero tengo que usarla-de tolerancia, pero no sólo tolerancia, sino también convivencia, amistad. (CP8). ${ }^{15}$
\end{abstract}

Em (3), constata-se que marcador conversacional de modalidade deôntica No é empregado pelo Papa Francisco para expressar o que é por ele avaliado como uma proibição em relação ao fato de os líderes religiosos católicos fazerem uso de seus púlpitos para a propagação de ideias e ideologias políticas. O valor modal de proibição, que ancora o marcador conversacional de modalidade deôntica, é reforçado pela modalidade epistêmica de avaliação (cree usted) que, por sua vez, tem um escopo de atuação sobre a modalidade deôntica de obrigação (los líderes religiosos deben intervenir más en el campo político) contida na pergunta feita pelo jornalista; sendo também reforçado pelas modalizações deônticas instauradas na resposta do Papa Francisco (hay que hacer una politica de unidad, de reconciliación e tengo que usarla).

Nota-se que as modalizações deônticas que ancoram o marcador conversacional No apresentam diferentes orientações modais. Enquanto a modalidade deôntica, que foi instaurada na pergunta feita pelo jornalista, está orientada para o Participante (o que assevera a obrigação do participante expresso em poder atuar mais no campo político), na resposta dada

15 Tradução livre: (Philippine De Saint-Pierre): Santo Padre, boa tarde. O senhor prestou homenagem à plataforma criada pelo arcebispo, pelo Imã e pelo pastor de Bangui, e hoje mais do que nunca sabemos que o fundamentalismo religioso ameaça todo o planeta: também o vimos em Paris. Dado esse perigo, o senhor acha que os líderes religiosos deveriam intervir mais no campo político? (Papa Francisco): Se intervir no campo político significa "fazer política", não. Servir como sacerdote, pastor, imã, rabino: esta é a sua vocação. Mas a política é feita indiretamente, pregando valores, valores verdadeiros e um dos maiores valores é a irmandade entre nós. Somos todos filhos de Deus, temos o mesmo Pai. Nesse sentido, devemos fazer uma política de unidade, reconciliação e - é uma palavra da qual não gosto, mas preciso usá-la - de tolerância, mas não apenas tolerância, mas também convivência, amizade. 
pelo Papa Francisco, encontra-se: (i) uma modalidade deôntica com orientação para o Evento, o que pode mitigar o comprometimento do Santo Padre em relação à permissão contida na predicação, e (ii) uma modalidade deôntica com orientação para o Participante, o que remete a uma obrigação interna instaurada pelo próprio Sumo Pontífice (o que é evidenciado pela marca de primeira pessoa do singular, tengo).

É importante salientar que outros marcadores conversacionais de modalidade deôntica poderiam expressar o que é avaliado como proibido pelo Papa Francisco, tais como: nunca, jamás, ni hablar, etc. Parafraseando o exemplo, isso pode ser verificado: Si intervenir en el campo politico significa «hacer politica», nunca/jamás/ni hablar.

Com base no que foi exposto anteriormente, apresenta-se o Quadro 02 que contém, em forma de resumo, o conceito de marcador conversacional de modalidade deôntica e os demais atributos que a ele competem:

Quadro 02: Os marcadores conversacionais de modalidade deôntica

\begin{tabular}{|c|c|c|}
\hline $\begin{array}{c}\text { Definição de marcador con- } \\
\text { versacional de modalidade } \\
\text { deôntica }\end{array}$ & $\begin{array}{c}\text { Tipos de modalidade que } \\
\text { podem ancorar o marcador } \\
\text { conversacional }\end{array}$ & \begin{tabular}{|c|} 
O valor modal que aporta o \\
marcador conversacional e os \\
tipos de marcadores \\
\end{tabular} \\
\hline \multirow{3}{*}{$\begin{array}{l}\text { os marcadores conversacionais } \\
\text { de modalidade deôntica refle- } \\
\text { tem as atitudes do falante no que } \\
\text { diz respeito às suas obrigações, } \\
\text { ao que é permitido ou proibido } \\
\text { de realizar frente ao que lhe é } \\
\text { proposto no discurso. }\end{array}$} & \multirow{3}{*}{$\begin{array}{l}\text { Geralmente, são ancorados por } \\
\text { modalizações epistêmicas e } \\
\text { deônticas, com orientação mo- } \\
\text { dal para o Participante e/ou o } \\
\text { Evento }\end{array}$} & $\begin{array}{l}\text { Obrigação: esto sí, por supuesto, } \\
\text { evidentemente, claro, de acuerdo, } \\
\text { etc. }\end{array}$ \\
\hline & & $\begin{array}{l}\text { Permissão: sí, por supuesto, evi- } \\
\text { dentemente, claro, de acuerdo, certa- } \\
\text { mente, etc. }\end{array}$ \\
\hline & & $\begin{array}{l}\text { Proibição: no, nunca, jamás, ni } \\
\text { hablar, etc. }\end{array}$ \\
\hline
\end{tabular}

Fonte: Elaborado pelo autor com base nos resultados e discussões

No que diz respeito aos marcadores conversacionais de modalidade volitiva, foi possível constatar que estes remetiam aos valores modais de desejo, vontade, intenção e afetividade-volitiva, como se pode atestar, respectivamente, de (4) a (7).

Em (4), discorre-se sobre um marcador conversacional volitivo com valor modal de desejo:

(Darío Menor Torres): ¿Se ha quedado con el deseo de visitar las Pirámides?

(Papa Francisco): ¿Pero tú sabes que hoy a las seis de la mañana mis dos asistentes se han ido a visitar las Pirámides?

(Dario Menor Torres): ¿Ah, sí? Pero, ¿le habría gustado ir con ellos?

(Papa Francisco): Si, ciertamente sí. (CP15). ${ }^{16}$

Em (4), comprova-se que o Santo Padre faz uso dos marcadores conversacionais sí e ciertamente para expressar seu desejo de haver visitado as pirâmides na época de sua viagem apostólica ao Egito. O valor modal de desejo é aplicado para este caso, tendo em vista a contrafactualidade daquilo que é volicionado, posto que já não seria possível que o Santo Padre realizasse o que ele voliciona, considerando que a viagem apostólica ao Egito já havia sido realizada na ocasião da entrevista. Nota-se também que os marcadores conversacionais de modalidade volitiva são ancorados por duas modalizações volitivas: El deseo de visitar las

16 Tradução livre: (Darío Menor Torres): O senhor ficou com o desejo de visitar as pirâmides? (Papa Francisco): Mas você sabe que hoje às seis da manhã meus dois assistentes foram visitar as pirâmides? (Darío Menor Torres): Ah, sim? Mas o senhor gostaria de ter ido com eles? (Papa Francisco): Sim, certamente sim. 
Pirámides e Le habría gustado ir con ellos; cuja orientação modal para o Participante reforça o desejo do Santo Padre que, por sua vez, é o participante expresso pelo predicado na segunda modalidade volitiva instaurada e aquele a quem o desejo se direciona na primeira modalidade volitiva instaurada.

É necessário dizer que outros marcadores conversacionais de modalidade volitiva poderiam ser empregados no intuito de que o falante expresse seus desejos, tais como: por supuesto, en absoluto, de verdad, evidentemente, claro, etc. Parafraseando o exemplo, isso pode ser apurado: (Dario Menor Torres): ¿Ah, sí? Pero, ¿le habría gustado ir con ellos? (Papa Francisco): Por supuesto/En absoluto/De verdad/Evidentemente/Claro.

Na sequência, aborda-se um caso de marcador conversacional de modalidade volitiva com valor modal de vontade:

(Jean-Louis): Y además otra pregunta: ¿Cabría la posibilidad de que usted fuera a Irak, quizás al Kurdistán, para apoyar a los refugiados cristianos, que le esperan, y para rezar con ellos en esa tierra donde viven desde hace dos mil años?

(Papa Francisco): Si, yo estaría dispuesto, pero puedo decir esto: cuando tuvimos noticia, mis colaboradores y yo, de la situación en que se encontraban las minorías religiosas, y también del problema, en aquel momento, del Kurdistán, que no podia recibir a tanta gente - se entiende que es un problema: no podia-, nos dijimos: ¿qué podemos hacer? Pensamos muchas cosas. (CP2). ${ }^{17}$

Em (5), evidencia-se que o Papa Francisco faz uso do marcador conversacional de modalidade volitiva Sí para expressar sua vontade de ajudar os refugiados e as minorias religiosas no Iraque e no Curdistão, cuja atenuação dessa vontade é ancorada pela modalidade volitiva com orientação modal para o Participante, que é articulada na resposta do Papa Francisco, no caso, Yo estaría dispuesto. O valor modal de vontade é aplicado a este caso, considerando que o evento volicionado pelo Santo Padre depende de fatores externos a ele, cuja concretização lhe foge ao controle, mas passível de ser localizado no tempo e no espaço se forem atendidas essas circunstâncias externas. Esses fatores externos, o que explica a não controlabilidade sobre o evento volicionado (ir ao Iraque e ao Curdistão) por parte do Sumo Pontífice, é reforçado pela modalidade epistêmica contida na pergunta feita pelo jornalista (Cabría la posibilidad de que usted fuera a Irak, quizás al Kurdistán) e pela modalidade facultativa (En aquel momento, del Kurdistán, que no podia recibir a tanta gente).

Nesse sentido, o uso da modalidade epistêmica remete à possibilidade de concretização do que é volicionado, enquanto a modalidade facultativa remete aos fatores externos, que impossibilitam que o evento volicionado se concretize. Em ambas as modalidades, a orientação modal está orientada para o Evento, o que não apenas descompromete o jornalista que faz a pergunta (na qual se encontra a modalidade epistêmica) como a pessoa do Papa Francisco (que reporta a impossibilidade de concretização do que é volicionado por meio da modalidade facultativa).

17 Tradução livre: (Jean-Louis): E outra pergunta: seria possível o senhor ir ao Iraque, talvez ao Curdistão, para apoiar os refugiados cristãos, que estão esperando pelo senhor, e orar com eles naquela terra em que vivem? por dois mil anos? (Papa Francisco): Sim, eu estaria disposto, mas posso dizer o seguinte: quando tivemos notícias, eu e meus colaboradores, da situação em que as minorias religiosas estavam, e também do problema, naquela época, do Curdistão, que não eu poderia receber tantas pessoas - entende-se que é um problema: eu não poderia - nós dissemos: o que podemos fazer? Pensamos muitas coisas. 
É possível inferir que outros marcadores conversacionais de modalidade volitiva poderiam ser empregados no intuito de que o falante expresse suas vontades, tais como: por supuesto, en absoluto, de verdad, evidentemente, claro, ciertamente, etc. Parafraseando o exemplo, isso pode ser constatado: Por supuesto/En absoluto/De verdad/Evidentemente/Claro/Ciertamente, yo estaría dispuesto.

Em (6), constata-se um caso de marcador conversacional de modalidade volitiva com valor modal de intenção:

(Fabio Zavattaro): Perdone, he tenido un pequeño inconveniente para llegar. Usted, Santo Padre, es el primer Papa que ha podido sobrevolar China. El telegrama que ha enviado al Presidente chino no ha recibido comentarios negativos. ¿Cree que éstos son pasos que permiten avanzar en un posible diálogo? ¿le gustaría viajar a China?

(Papa Francisco): ¿Que si me gustaría ir a China? Por supuesto: jmañana! Sí. Respetamos al pueblo chino; la Iglesia pide únicamente libertad para su misión, para llevar a cabo su tarea; no hay más condiciones. (CP2). ${ }^{18}$

Em (6), contata-se que o Papa Francisco faz uso de dois tipos de marcadores conversacionais de modalidade volitiva, por supuesto e sí, para manifestar, ao seu ouvinte, a intenção de realizar uma viagem apostólica à China. $O$ valor modal de intenção é atribuído a esses marcadores conversacionais em virtude da controlabilidade do evento por parte do Santo Padre. Isso se justifica, tendo em vista o telegrama enviado pelo presidente da China ao Sumo Pontífice, o que poderia garantir uma possível viagem apostólica ao país asiático. Ambos os marcadores conversacionais de modalidade volitiva são ancorados por modalizações volitivas com orientação modal para o Participante, o que garante a relação entre o participante expresso (Papa Francisco) e a concretização do evento por parte dele, o que também é reforçado pelos verbos performativos que os modalizadores volitivos tomam por escopo, em questão, viajar e ir. ¿Le gustaría viajar a China? e ¿Que si me gustaría ir a China?.

É plausível dizer que outros marcadores conversacionais de modalidade volitiva poderiam ser empregados no intuito de que o falante expresse suas intenções, tais como: concretamente, en absoluto, de verdad, evidentemente, claro, ciertamente, etc. Parafraseando o exemplo, isso pode ser averiguado: ¿Que si me gustaría ir a China? Concretamente/En absoluto/De verdad/ Evidentemente/Claro/Ciertamente: ¡mañana! Sí.

Em (7), discorre-se acerca de um caso de marcador conversacional volitivo com valor modal do tipo afetivo-volitivo:

(Ludwig Ring-Eifel): Santidad, dentro de pocas semanas usted recibirá el Premio Carlo Magno, uno de los premios más prestigiosos de la Comunidad Europea. También su predecesor, san Juan Pablo II, recibió este premio; era importante para él. A él también le importaba mucho la unidad europea, que ahora parece que se está rompiendo a trozos, primero con la crisis del euro y ahora con la crisis de los refugiados. ¿Tiene una palabra para nosotros en esta situación de crisis europea?

(Papa Francisco): Y he pensado en los grandes padres... pero, hoy, ¿dónde hay un Schuman, un Adenauer? Estos grandes, que en la postguerra han fundado la Unión Europea. Y me gusta esta idea de la refundación. ;Ojalá se pueda hacer! Porque Europa, no diría que es única, pero

18 Tradução livre: (Fabio Zavattaro): Com licença, tive um pequeno inconveniente para chegar. O senhor, Santo Padre, é o primeiro Papa que conseguiu sobrevoar a China. O telegrama que o senhor enviou ao presidente chinês não recebeu comentários negativos. O senhor acha que essas são etapas que permitem o progresso para um possível diálogo? O senhor gostaria de viajar para a China? (Papa Francisco): E se eu gostaria de ir para a China? Claro: amanhã! Sim. Nós respeitamos o povo chinês; a Igreja pede apenas liberdade para sua missão, para cumprir sua tarefa; não há mais condições. 
tiene una fuerza, una cultura, una historia que no se puede despreciar, y tenemos que hacer todo para que la Unión Europea tenga la fuerza y también la inspiración de hacernos caminar hacia delante. No sé: esto es lo que pienso. (CP9). ${ }^{19}$

Em (7), averígua-se que o Papa Francisco faz uso de um marcador conversacional de modalidade volitiva do tipo afetivo-volitivo, no caso, ojalá+subjuntivo, para expressar a desejabilidade que recai sobre o evento contido na ilocução optativa: a refundação e unificação da União Europeia. O valor modal afetivo-volitivo empregado é ancorado por meio de duas modalizações deônticas, uma com orientação para o Evento, com valor modal de proibição (Una fuerza, una cultura, una historia que no se puede despreciar) e uma com orientação modal para o Participante com valor modal de obrigação (Tenemos que hacer todo para que la Unión Europea tenga la fuerza y también la inspiración de hacernos caminar hacia delante). A distinção entre as orientações modais na instauração das modalizações deônticas asseveram o valor modal afetivo-volitivo do marcador conversacional volitivo, haja vista que há a instauração de uma proibição em relação ao evento contido na predição (que não se menospreze a força, a cultura e a história europeia), que se aplica ao participante expresso na modalidade com orientação para o Participante que, por sua vez, está sob a obrigação de fazer todo o possível para que a União Europeia tenha forças. Com a performatização desses estados-de-coisas, é possível que haja a concretização do que é desejado pelo Sumo Pontífice, em questão, a refundação e a unificação da União Europeia.

É aceitável mencionar que outros marcadores conversacionais de modalidade volitiva poderiam ser empregados no intuito de que o falante expressasse seus afetos, tais como outras construções volitivas: que+subjuntivo, hacer votos etc. Parafraseando o exemplo, isso pode ser verificado: ¡Qué se pueda hacer! / „Hago votos que se pueda! Porque Europa, no diría que es única, pero tiene una fuerza, una cultura, una historia que no se puede despreciar.

A partir do que foi abordado acerca dos marcadores conversacionais de modalidade volitiva, apresenta-se o Quadro 03 que contém, em forma de resumo, tanto o conceito de marcador conversacional de modalidade volitiva quanto os demais atributos que a ele competem:

Quadro 03: Os marcadores conversacionais de modalidade volitiva

\begin{tabular}{|l|l|}
\hline $\begin{array}{c}\text { Definição de marcador conversacional de mo- } \\
\text { dalidade volitiva }\end{array}$ & $\begin{array}{l}\text { Tipos de modalidade que podem ancorar o mar- } \\
\text { cador conversacional }\end{array}$ \\
\hline $\begin{array}{l}\text { os marcadores conversacionais de modalidade de } \\
\text { volitiva refletem as atitudes do falante no que diz } \\
\text { respeito aos seus afetos, desejos, vontades e inten- } \\
\text { ções frente ao que lhe é proposto no discurso. }\end{array}$ & $\begin{array}{l}\text { Geralmente, são ancorados por modalizações } \\
\text { epistêmicas, facultativas, volitivas e deônticas, } \\
\text { com orientação modal para o Participante e/ou } \\
\text { o Evento. }\end{array}$ \\
\hline \multicolumn{2}{|c|}{ O valor modal que aporta o marcador conversacional volitivo e os tipos de marcadores } \\
\hline $\begin{array}{l}\text { Desejo - marcadores que remetam a eventos localizados apenas na mente do falante: sí, ciertamente, } \\
\text { por supuesto, en absoluto, de verdad, evidentemente, claro, etc. }\end{array}$ \\
\hline
\end{tabular}

19 Tradução livre: (Ludwig Ring-Eifel): Santidade, em poucas semanas o senhor receberá o Prêmio Carlo Magno, um dos mais prestigiados da Comunidade Europeia. Também seu antecessor, São João Paulo II, recebeu este prêmio; era importante para ele. Ele também se importava muito com a unidade europeia, que agora parece estar se rompendo, primeiro com a crise do euro e agora com a crise dos refugiados. O senhor tem uma palavra para nós nesta situação de crise europeia? (Papa Francisco): E pensei nos grandes países ... mas hoje, onde há um Schuman, um Adenauer? Esses grandes, que no período pós-guerra fundaram a União Europeia. E eu gosto dessa ideia de refundação. Oxalá isso possa ser feito! Porque a Europa não diria que é única, mas tem uma força, uma cultura, uma história que não pode ser negligenciada, e temos que fazer tudo para que a União Europeia tenha a força e também a inspiração para nos fazer avançar. Não sei: é isso que eu acho. 
Vontade - marcadores que remetem a eventos passíveis de concretização no mundo real, mas dependentes de fatores externos ao falante: sí, por supuesto, en absoluto, de verdad, evidentemente, claro, ciertamente, etc.

Intenção - marcadores que remetem a eventos controlados por parte do falante: por supuesto, sí, concretamente, en absoluto, de verdad, evidentemente, claro, ciertamente, etc.

Afetivo-volitivo - marcadores que remetem a eventos relacionados aos afetos do falante: ojalá +subjuntivo, que+subjuntivo, hacer votos, tener ganas, etc.

Fonte: Elaborado pelo autor com base nos resultados e discussões

A partir da descrição e análise qualitativa dos marcadores conversacionais de modalidade deôntica e volitiva, é possível compreender que há uma distinção de valores semânticos (afeto, desejo, vontade, intenção, obrigação, permissão e proibição) que podem ser articulados no discurso, tendo em vista outros fatores, tais como o tipo de modalidade instaurada (epistêmica, deôntica, facultativa e volitiva) e o tipo de orientação modal (Participante e Evento) que ancoram o marcador conversacional empregado pelo falante em seu encadeamento discursivo.

\section{CONSIDERAÇÕES FINAIS}

A partir da descrição e análise empreendida nesta pesquisa, constata-se que, por meio da tipologia das modalidades de Hengeveld (2004), foi possível que se redefinisse os marcadores conversacionais de modalidade deôntica, delimitando-os como aqueles que refletem as atitudes do falante em relação às suas obrigações, ao que é permitido ou proibido de realizar frente ao que lhe é proposto no discurso, sendo ancorados, geralmente, por modalizações epistêmicas e deônticas, com orientação modal para o Participante e/ou o Evento e relativos aos valores modais de obrigação, permissão e proibição; e propondo os marcadores conversacionais de modalidade volitiva, especificando-os como aqueles que refletem as atitudes do falante no que diz respeito aos seus afetos, desejos, vontades e intenções frente ao que lhe é proposto no discurso, sendo ancorados por modalizações epistêmicas, facultativas, volitivas e deônticas, com orientação modal para o Participante e/ou o Evento e relativos a valores como desejo, vontade, intenção e afeto.

\section{CONVERSATIONAL MARKERS OF DEONTIC AND VOLITIVE MODALITY: A READJUSTMENT PROPOSAL BASED ON HENGEVELD (2004)}

RESUMO: This work aims to describe and analyse the existence of conversational markers of volitive modality from what is traditionally proposed about conversational markers of deontic modality. In this sense, the necessary theoretical foundation was sought in the types of modalities proposed by Hengeveld (2004). For this, the interviews given by Pope Francis at the Conferencias de Prensa carried out during his apostolic journeys were used. After reading the interviews that made up the corpus and based on the types of conversational markers of deontic modality found, it was defined that the conversational markers of volitive modality refer to the speaker's affections, desires, wishes and intentions in face of what is proposed to him in discursive interaction; while those of deontic modality reflect the obligations, permissions and prohibitions inherent in the speaker or the events described at the time of speech.

KEYWORDS: Conversational Markers. Deontic modality. Volitive Modality.

\section{REFERÊNCIAS}

ABARCA CEA, Claudia. Operadores discursivo-pragmáticos en consultas cartománticas. Revista 
de Humanidades, n. 26, p. 143-158, 2012. Disponível em: http://revistahumanidades.unab.cl/wpcontent/uploads/2013/01/A7.ABARCA.pdf. Acesso em: 29 dez. 2019.

ÁLVAREZ-EJZENBERG, Fabiana. El marcador discursivo dale desde la perspectiva de la unicidad del signo. Círculo de Lingüística Aplicada a la Comunicación, n. 62, p. 54-75, 2015. Disponível em: https://revistas.ucm.es/index.php/CLAC/article/view/49498/

46063. Acesso em: 29 dez. 2019.

FOLKESSON, Elisabet. Bueno... ¡hombre! ¡Qué conversación!: un estudio sobre los marcadores discursivos conversacionales en los libros de enseñanza en Suecia. 2014. 28f. Monografia (Faculdade de Línguas) - Departamento de Línguas Modernas, Universidade Uppsala, Suécia, 2019.

HENGEVELD, K. Illocution, mood, and modality. In: BOOIJ, G.; LEHMANN, C.; MUGDAN, J. Morphology: a handbook on inflection and word formation. Berlin: Mouton de Gruyter, p.11901201, 2004.

LEÓN-CASTRO, Marta. La oralidad como estrategia de acercamiento al lector en la columna periodística de Antonio Burgos. Anuario de Letras, Lingüística y Filología, v. 7, p. 33-62, 2019. Disponível em: https://revistas-filologicas.unam.mx/anuario-letras/index.php/al/article/ view/1551/1959. Acesso em: 29 dez. 2019.

MENDOZA, José García. Marcadores discursivos en La Paz. Cuadernos de la ALFAL, n. 5, p. 140162, 2014. Disponível em: https://mundoalfal.org/sites/default/files/revista

/05_cuaderno_006.pdf. Acesso em: 29 dez. 2019.

MOLERO HERMOSILLA, Antonio José. La conferencia de prensa: una herramienta fundamental para el éxito de la relaciones informativas. 2005. Disponível em: https://docplayer.es/5117673-Laconferencia-de-prensa-una-herramienta-fundamental-para-el-exito-de-la-relaciones-informativasantonio-jose-molero-hermosilla-aj_molero-yahoo.html. Acesso em: 29 dez. 2020.

OLIVEIRA, André Silva. Os marcadores conversacionais de modalidade deôntica nas entrevistas do Papa Francisco. Revista Miguilim, v. 8, n. 1, p. 04-23, 2019. Disponível em: http://periodicos.urca. br/ojs/index.php/MigREN/article/view/1782/1378. Acesso em: 29 dez. 2019.

SAÍZ, Carmen Llamas; PASAMAR, Concha Martínez. Hombre, enseñar español no es tan fácil: la enseñanza del enfocador de alteridad hombre. In: MAESTU, Enrique Balmaseda (Org.). Las destrezas orales en la enseñanza del español L2-LE: XVII Congreso Internacional de la Asociación del Español como lengua extranjera (ASELE), Madrid: Universidad de La Rioja, 2012.

VALENCIA, Alba. Más sobre marcadores hispánicos: usos de España y América en el Corpus de estudio de la norma culta. Cidade do México: Universidade Autônoma do México, 2015.

ZORRAQUINO, María Antonia Martín; PORTOLÉS, José Lázaro. Los marcadores del discurso. In: BOSQUE, Ignacio; DEMONTE, Violeta. Gramática descriptiva de la lengua española. Madri: Espasa Calpe, p. 4051-4213, 1999. 